\title{
A new method to calculate sweep efficiency of horizontal wells in heterogeneous reservoir
}

\author{
Y. C. Su ${ }^{1} \cdot$ H. F. Shi ${ }^{1} \cdot$ Y. F. $\mathrm{He}^{1}$
}

Received: 12 April 2018 / Accepted: 26 November 2018 / Published online: 3 December 2018

(c) The Author(s) 2018

\begin{abstract}
This paper discusses the development challenges of an offshore fluvial oil reservoir with horizontal wells. In highly productive sandstone reservoirs, horizontal wells suffer from uneven flow profile and subsequent premature coning effects because of sand heterogeneity and heel to toe effect. Moreover, excessively increasing the production rate or horizontal well length can increase the risk of limited sweep efficiency, resulting in remaining oil in the toe or poor sand with low permeability. First, we analyze the characters of fluvial oil reservoir focusing on sand architecture and heterogeneity. Second, the sweep efficiency was calculated by the production data. Finally, we optimize inflow control device (ICD) for several wells and compare the response of ICD wells with conventional screen completion wells.
\end{abstract}

Keywords Fluvial oil reservoir · Heterogeneity · Horizontal wells · Sweep efficiency · Inflow control device

\section{Introduction}

Q \& C oilfields are two large heavy oil fluvial reservoirs located at Bohai Bay in China, characterized as having excellent reservoir quality (up to $30 \%$ porosity and $3000 \mu^{2}$ permeability), strong heterogeneity, low oil columns (6-15 m), strong bottom water drive with large energy, widely used horizontal wells, and high liquid production of single well (average $800 \mathrm{~m}^{3} /$ day) (Fig. 1). After 15 years of development, many wells show sharp production decline and rapid water cut increase. At present, water breakthrough in several wells is much earlier than prediction. The high mobility ratio, heel-toe effect, bottom water, permeability heterogeneity and sand production contribute to low ultimate recovery and short well life. How can water breakthrough be delayed and significantly improve the economic life of the wells? This is especially important for offshore fields where well intervention is difficult and expensive. What's more, one of the biggest technological challenges is the capacity of platform, Floating Production Storage and Offloading (FPSO) and power. How can we control the water and make the oil production stable?

$\triangle$ H. F. Shi

cnoocbohai@126.com

1 Tianjin Branch, National Offshore Oil Corporation, Tianjin 300459, China

\section{Reservoir description}

There are many horizontal wells in offshore oilfield, this can help us identify abandoned channel and point bar according to their electronic property. More than 500 wells' drilling data shows that the point bar in this area is between 200 and $500 \mathrm{~m}$. The real drilling results also show some horizontal wells across different point bar and abandoned channel, as shown in Fig. 2 logging data of G30H.

It can be predicted that the production of horizontal section with a low permeability will be poor; the time of bottom water breaks through time will be totally different. Just like the interlayer interference of directional wells, there is interference between different sections of horizontal wells. The section interference depends on sand permeability, oil saturation, draw down and bottom aquifer. In other words, the difference of static permeability and dynamic production data will aggravate the "section interference" which also reduces the sweep efficiency of horizontal wells and recovery factor.

\section{Dynamic production data analysis}

It is difficult to obtain the actual output profile of horizontal segment in the production process as high risk of test. Moreover, it is unrealistic to get the production profile of each horizontal well due to high cost and limited space of platforms. However, high-resolution seismic data, hundreds

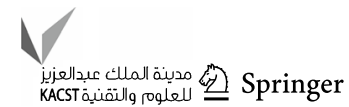




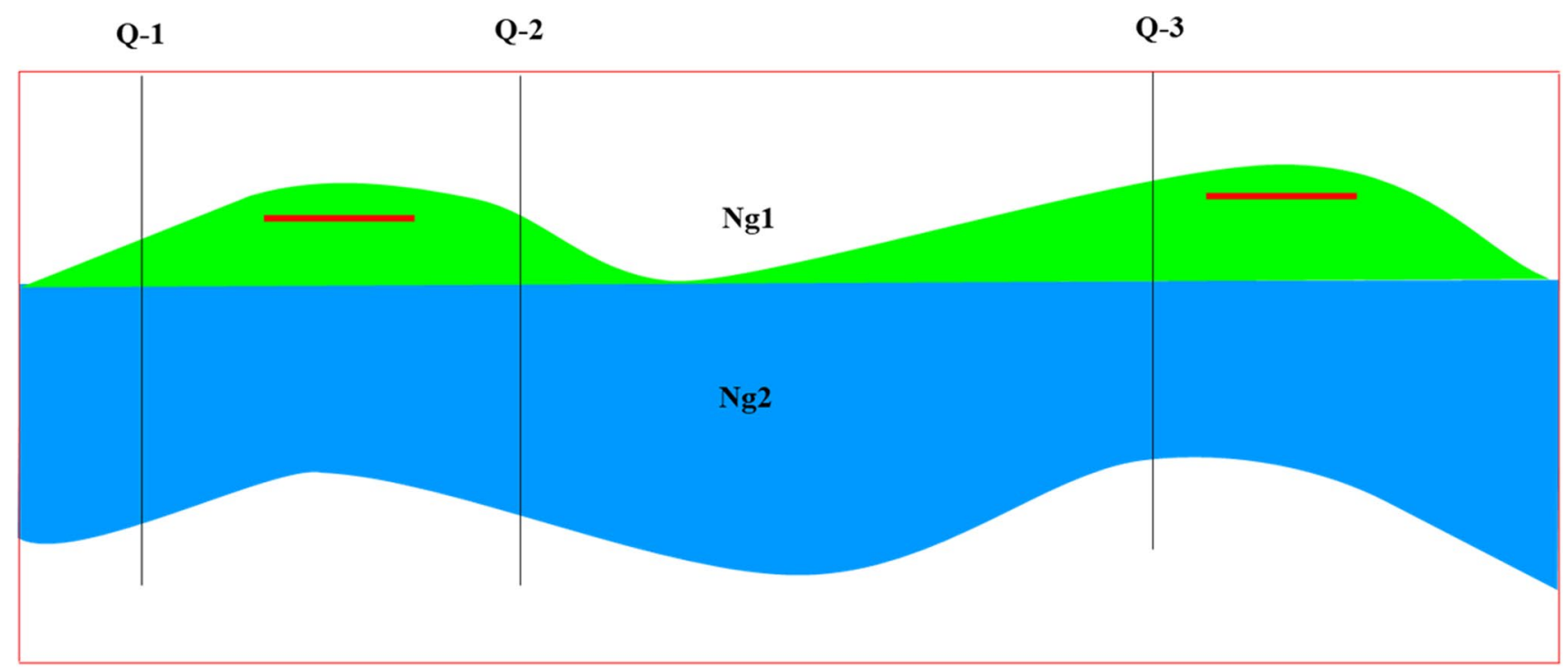

Fig. 1 The reservoir profile map of Q oilfield

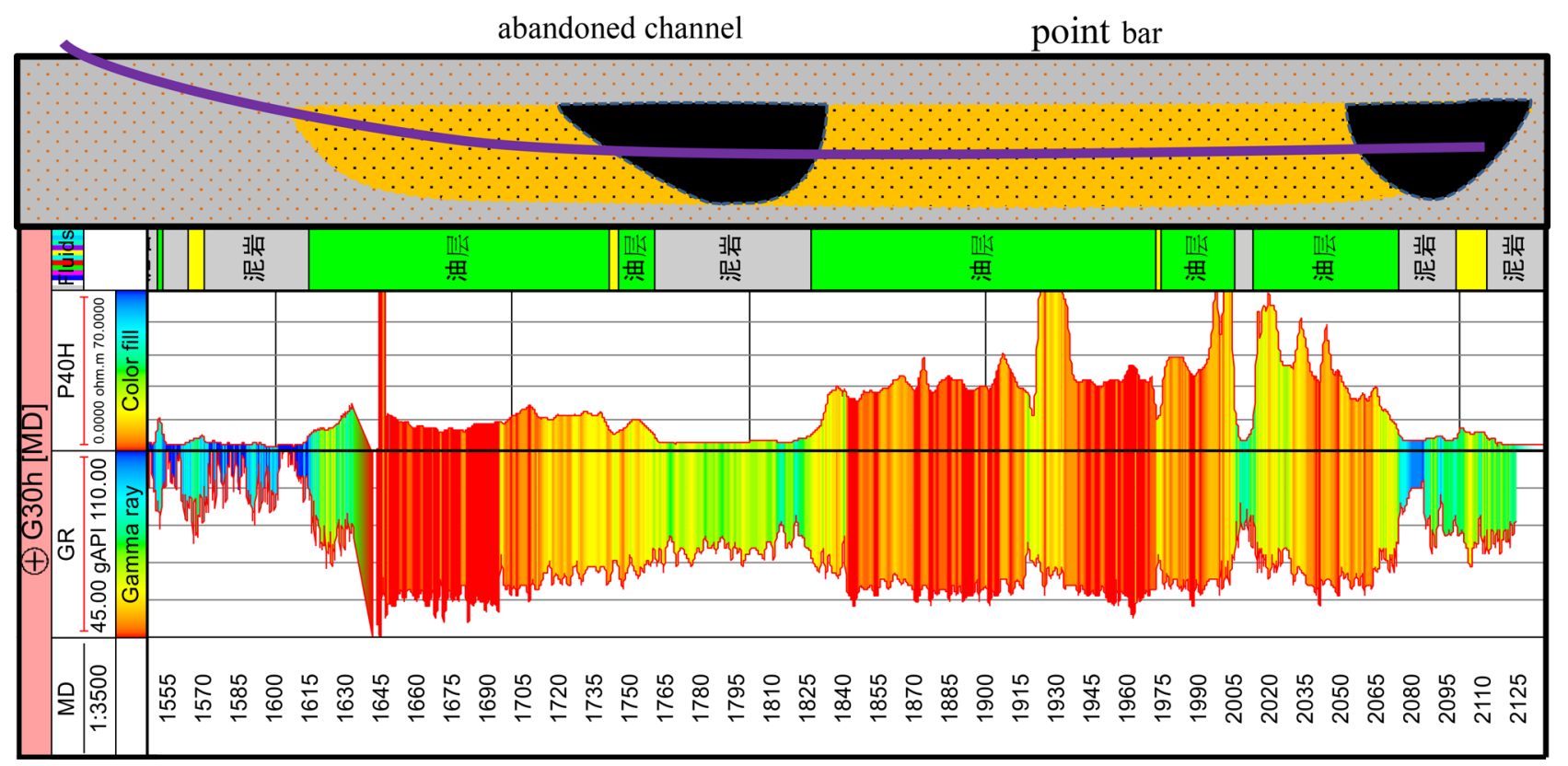

Fig. 2 The GR curve of G30H horizontal section

of horizontal wells, mass production data lay a strong foundation for production profile prediction. It is necessary to find a quick, simple and low-cost method to estimate the production profile of horizontal wells (Chen and Olynyk 1985; Araque-Martinez and Lake 1994). A new method named Tong's water flooding curve is proposed to evaluate the sweep efficiency of horizontal wells which can guide the further development and optimization.

The water flooding curve is a very popular method in China for evaluation of water flooding effect, regularities of water cut growth and prediction of recoverable reserves. The main assumptions are as follows: formation temperature and oil viscosity constancy, infinity water drive and formation pressure stabilization, no gas gap and gas channeling, following Darcy's law, without regard to capillary force (Mozaffari et al. 2015, 2017). We gave a detailed derivation process of this method.

The relationship between relative permeability and water saturation in oil-water flow is as below:

$\frac{k_{\mathrm{ro}}}{k_{\mathrm{rw}}}=d \mathrm{e}^{-c S_{\mathrm{w}}}$, 
where $k_{\mathrm{ro}}$ and $k_{\mathrm{ro}}$ are oil and water relative permeability; $S_{\mathrm{w}}$ is water saturation; $c$ and $d$ are constants of fluid and sand.

$\frac{k_{\mathrm{ro}}}{k_{\mathrm{rw}}}=\frac{Q_{\mathrm{o}} \mu_{\mathrm{o}} B_{\mathrm{o}} \rho_{\mathrm{w}}}{Q_{\mathrm{w}} \mu_{\mathrm{w}} B_{\mathrm{w}} \rho_{\mathrm{o}}}$,

where $Q_{\mathrm{o}}$ and $Q_{\mathrm{w}}$ are oil and water daily production rates $\mathrm{m}^{3} / \mathrm{day} ; \mu_{\mathrm{o}}$ and $\mu_{\mathrm{o}}$ are underground oil and water viscosities $\mathrm{mPa} \cdot \mathrm{s} ; B_{\mathrm{o}}$ and $B_{\mathrm{o}}$ are underground oil and water volume factors; $\rho_{\mathrm{o}}$ and $\rho_{\mathrm{o}}$ are surface oil and water densities $\mathrm{kg} / \mathrm{m}^{3}$.

$$
\begin{gathered}
\mathrm{WOR}=\frac{Q_{\mathrm{w}}}{Q_{\mathrm{o}}}=\frac{k_{\mathrm{rw}} \mu_{\mathrm{o}} B_{\mathrm{o}} \rho_{\mathrm{w}}}{k_{\mathrm{ro}} \mu_{\mathrm{w}} B_{\mathrm{w}} \rho_{\mathrm{o}}}=\frac{\mu_{\mathrm{o}} B_{\mathrm{o}} \rho_{\mathrm{w}}}{d \mu_{\mathrm{w}} B_{\mathrm{w}} \rho_{\mathrm{o}}} \mathrm{e}^{c S_{\mathrm{w}}} \\
\Rightarrow \quad Q_{\mathrm{w}}=Q_{\mathrm{o}} \frac{\mu_{\mathrm{o}} B_{\mathrm{o}} \rho_{\mathrm{w}}}{d \mu_{\mathrm{w}} B_{\mathrm{w}} \rho_{\mathrm{o}}} \mathrm{e}^{c S_{\mathrm{w}}}
\end{gathered}
$$

where WOR is water-oil ratio.

$W_{\mathrm{p}}=\int_{0}^{t} Q_{\mathrm{w}} \mathrm{d} t=\frac{\mu_{\mathrm{o}} B_{\mathrm{o}} \rho_{\mathrm{w}}}{d \mu_{\mathrm{w}} B_{\mathrm{w}} \rho_{\mathrm{o}}} \int_{0}^{t} Q_{\mathrm{o}} \mathrm{e}^{c S_{\mathrm{w}}} \mathrm{d} t$,

$N_{\mathrm{p}}=100 A h \phi \frac{\rho_{\mathrm{o}}}{B_{\mathrm{oi}}}\left(S_{\mathrm{w}}-S_{\mathrm{wc}}\right)$,

$W_{\mathrm{p}}$ is cumulative water production $10^{4} \times \mathrm{m}^{3} ; N_{\mathrm{p}}$ is cumulative oil production $10^{4} \times \mathrm{m}^{3} ; A$ is area of reservoir $\mathrm{km}^{2} ; h$ is net pay thickness of sand $\mathrm{m} ; S_{\mathrm{wc}}$ is irreducible water saturation; $N$ is initial oil in place $10^{4} \times \mathrm{m}^{3}$.

$Q_{\mathrm{o}}=\frac{\mathrm{d} N_{\mathrm{p}}}{\mathrm{d} t}=100 A h \phi \frac{\rho_{\mathrm{o}}}{B_{\mathrm{oi}}} \frac{\mathrm{d} S_{\mathrm{w}}}{\mathrm{d} t}$,

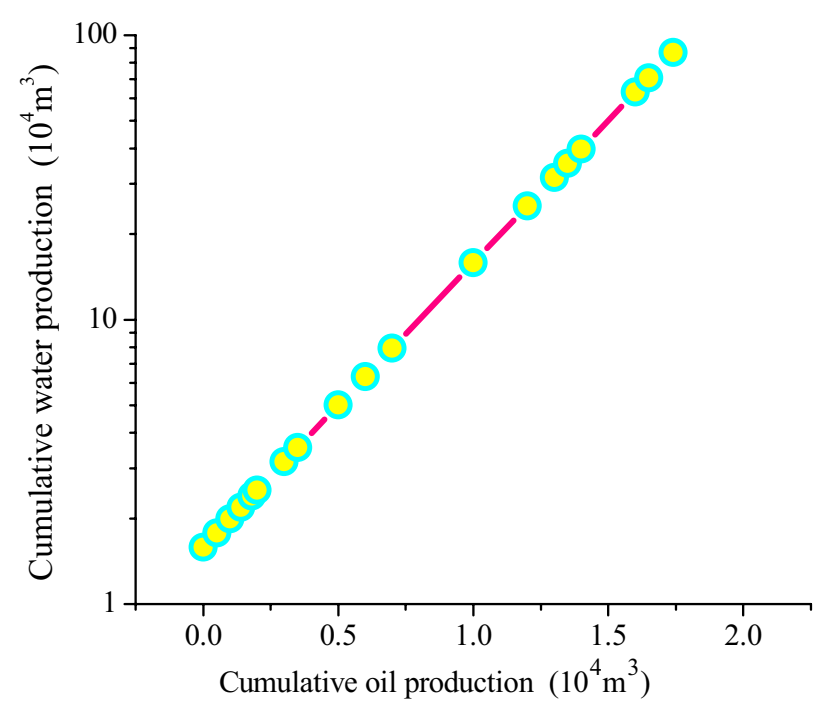

(a) Cumulative water VS cumulative oil

$$
\begin{aligned}
W_{\mathrm{p}} & =100 A h \phi \frac{\rho_{\mathrm{o}}}{B_{\mathrm{oi}}} \frac{\mu_{\mathrm{o}} B_{\mathrm{o}} \rho_{\mathrm{w}}}{d \mu_{\mathrm{w}} B_{\mathrm{w}} \rho_{\mathrm{o}}} \int_{S_{\mathrm{wc}}}^{S_{\mathrm{w}}} \mathrm{e}^{c S_{\mathrm{w}}} \mathrm{d} S_{\mathrm{w}} \\
& =100 A h \phi \frac{\rho_{\mathrm{o}}}{B_{\mathrm{oi}}} \frac{\mu_{\mathrm{o}} B_{\mathrm{o}} \rho_{\mathrm{w}}}{c d \mu_{\mathrm{w}} B_{\mathrm{w}} \rho_{\mathrm{o}}}\left(\mathrm{e}^{c S_{\mathrm{w}}}-\mathrm{e}^{c S_{\mathrm{wc}}}\right),
\end{aligned}
$$

$a=\lg M+\frac{c S_{\mathrm{wc}}}{2.3} ; \quad b=\frac{c}{2.3} \frac{\left(1-S_{\mathrm{wc}}\right)}{\xi}$,

$\lg \left(W_{\mathrm{p}}+\zeta\right)=a+b N_{\mathrm{p}}$,

where $M, \xi, a$ and $b$ are constants.

$$
\begin{aligned}
N_{\mathrm{p}} & =N \cdot R_{\mathrm{f}} \\
\lg \left(W_{\mathrm{p}}+\xi\right) & =a+b N_{\mathrm{oi}} \cdot R_{\mathrm{f}} \\
f_{w} & =\frac{\mathrm{WOR}}{1+\mathrm{WOR}}=\frac{1}{1+\frac{1}{\mathrm{WOR}}},
\end{aligned}
$$

where $R_{\mathrm{f}}$ is recovery percentage; $f_{\mathrm{w}}$ is water cut.

From Eq. (9), we can figure out the line relationship between $\lg \left(W_{\mathrm{p}}+\zeta\right)$ and $N_{\mathrm{p}}$ which is shown in Fig. 3a. We can also replace cumulative oil production by recovery percentage in $X$-axis and cumulative water production by water cut in $Y$-axis, as shown in Fig. 3b. In my paper, this method is used to analyze sweep efficiency of super-long horizontal wells.

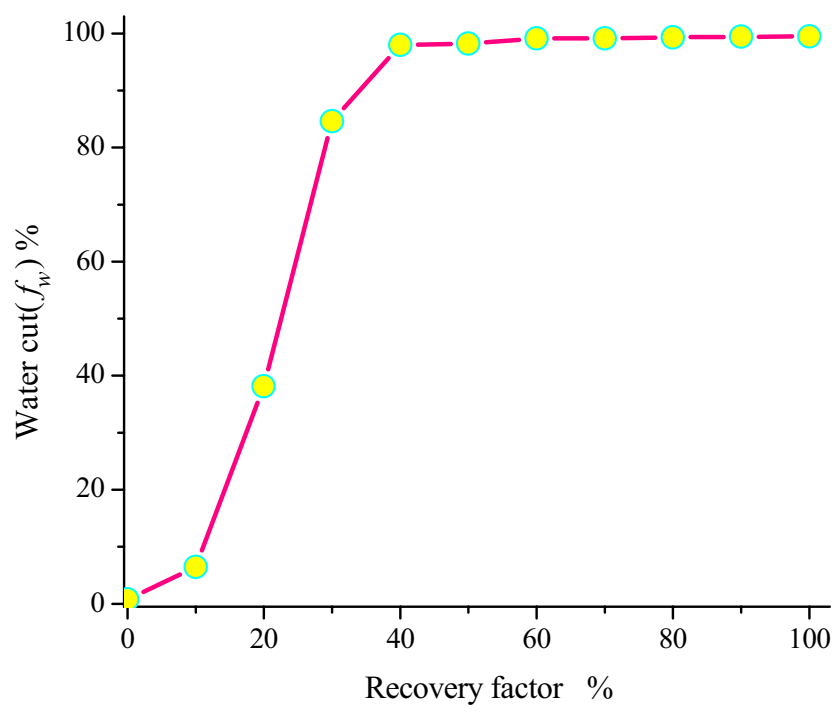

(b) water cut VS recovery factor

Fig. 3 The Tong's water flooding curve 


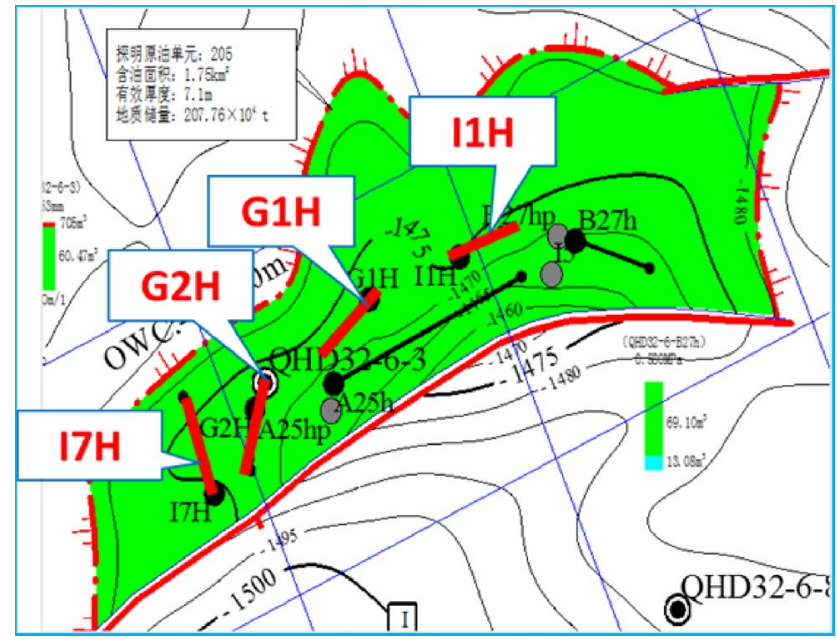

(a) well locations

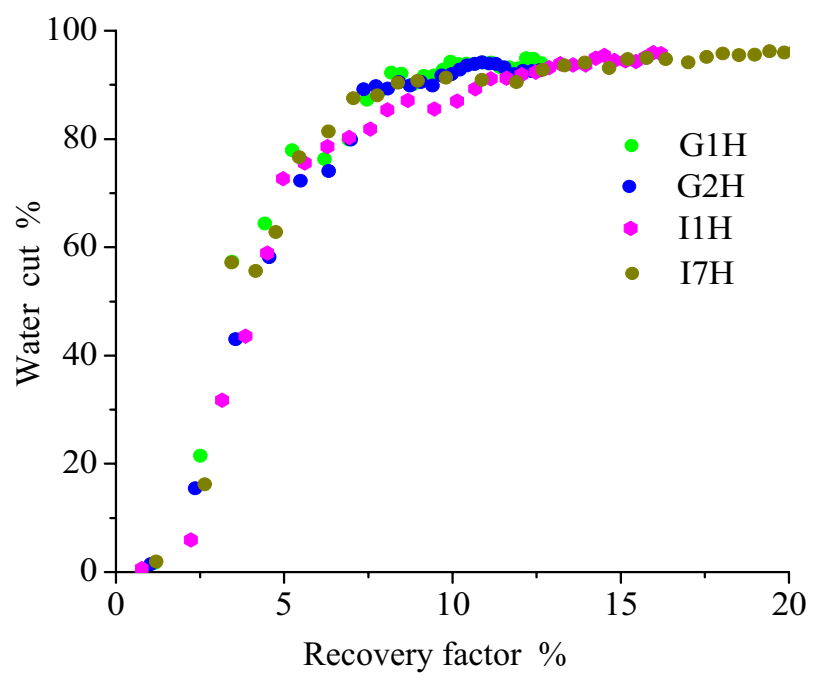

(b) production data

Fig. 4 The well location map and relation curve between water cut and recovery factor $\mathrm{Ng} 1$

According to the big data statistics and theoretical research, horizontal wells will show the same water cut increasing rule with similar physical properties, viscosity, oil columns and electric submersible pump. Figure 4 was taken as the first example, four horizontal wells in the same sand body, horizontal section length is slightly different (280-320 m), and the relationship between water cut and recovery factor is almost identical.

There are two key parameters in Fig. 4b. The first one is water cut $\left(f_{\mathrm{w}}\right)$ of production well which was from measured data easily. The second one is recovery factor $\left(R_{\mathrm{f}}\right)$, which was calculated by initial oil reserves controlled by each production well $\left(N_{\mathrm{oi}}\right)$ and cumulative oil production $\left(C_{\text {op }}\right)$ of each well. By the way, $N_{\text {oi }}$ is controlled by well length and oil column thickness:

$$
\begin{aligned}
R_{\mathrm{f}} & =\frac{C_{\mathrm{op}}}{N_{\mathrm{oi}}} \\
N_{\mathrm{oi}} & =\frac{\mathrm{A} \cdot h \cdot \phi \cdot\left(1-S_{\mathrm{wi}}\right) \rho_{\mathrm{o}}}{B_{\mathrm{oi}}},
\end{aligned}
$$

where $A$ oil area controlled by single production well; $h$ the average net thickness; $\phi$ the average effective porosity;

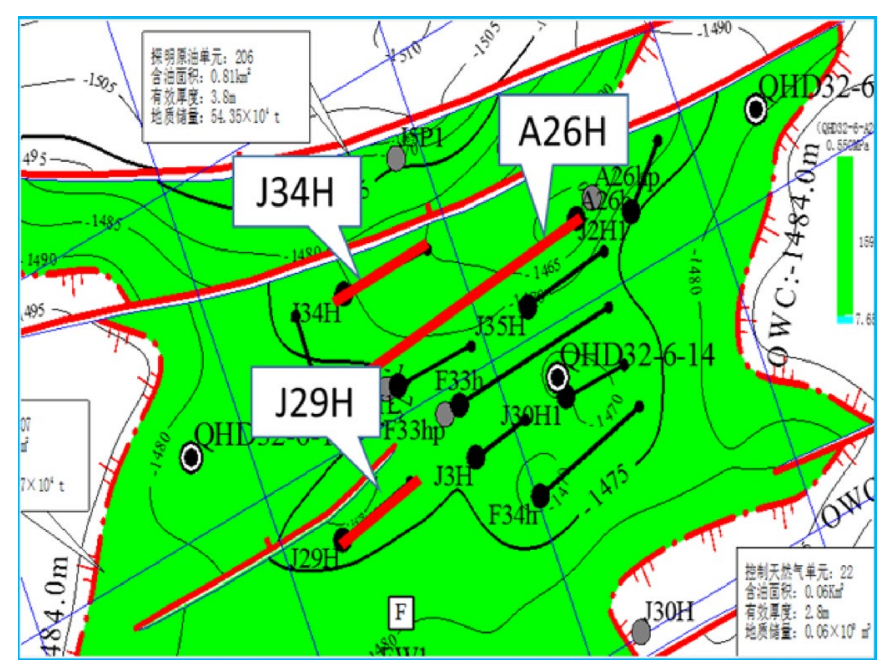

(a) well location

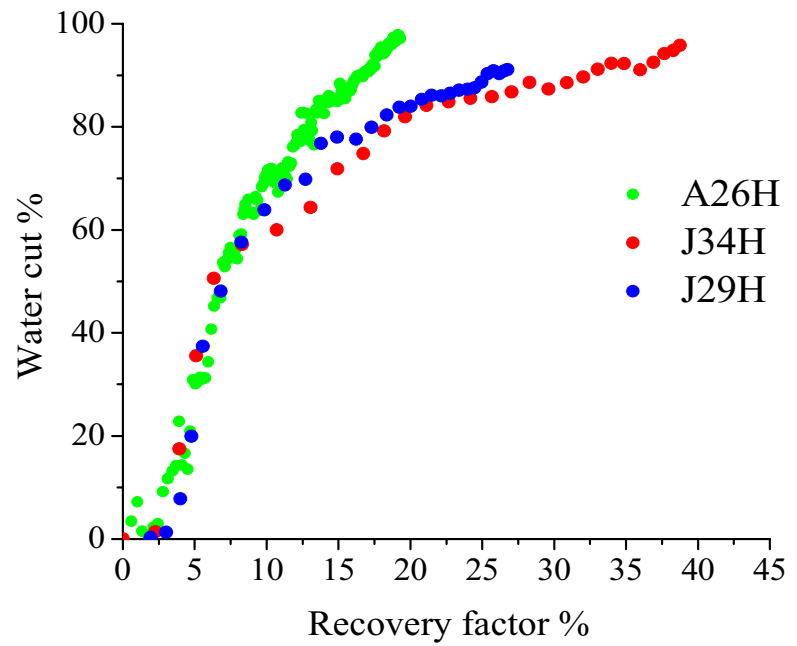

(b) production data

Fig. 5 The well location map and relation curve between water cut and recovery factor of $\mathrm{Ng} 2$ 
$S_{\mathrm{wi}}$ the irreducible water saturation; $\rho_{\mathrm{o}}$ the oil density; $B_{\mathrm{oi}}$ volume factor.

Figure 5 was taken as the second example, the relation curve between the water cut and the recovery factor of A26H well is inconsistent with another two wells and the coincidence is very poor especially in high water cut stage. The actual drilling data reveal that the length of $\mathrm{J} 34 \mathrm{H}$ well and $\mathrm{J} 29 \mathrm{H}$ is about $300 \mathrm{~m}$ while length of the $\mathrm{A} 26 \mathrm{H}$ well is $900 \mathrm{~m}$. Moreover, the horizontal section of the J34H well and $\mathbf{J} 29 \mathrm{H}$ well is homogeneous, located at a single point bar. Nevertheless, the trajectory of A26H was drilled in a point bar and abandoned river channel with obvious heterogeneity.

The unbalance production profile not only restrains the horizontal well productivity, reduces sweep efficiency along the well trajectory, results in bypassed remaining oil but also decreases the ultimate recovery factor (Dashash et al. 2008). An analogy method was adopted to identify the effective length of horizontal well and to locate the remaining oil section. First, two types of reserves were defined.

$\alpha=\frac{N_{\mathrm{oi}}}{N_{\mathrm{ai}}}$

$N_{\text {oi }}$ the initial oil reserves in a static state controlled by well length; $N_{\text {oa }}$ the actual oil reserves estimated by dynamic production data; $\alpha$ the reserve utilization coefficient.

A method named "piecewise fitting" was used to estimate the actual effective oil reserves in different water cut stages. As a result, the reserve utilization coefficient $(\alpha)$ can be obtained (Fig. 6). The reserve utilization coefficient decreases with the increment of water cut. It indicates that the "section interference" is exacerbated by water cut. The excessively increasing horizontal well length can increase the risk of limiting sweep efficiency (Onur Balan et al. 2016; Mozaffari et al. 2017). The following method must be present to find a balance between the well length and sweep efficiency.
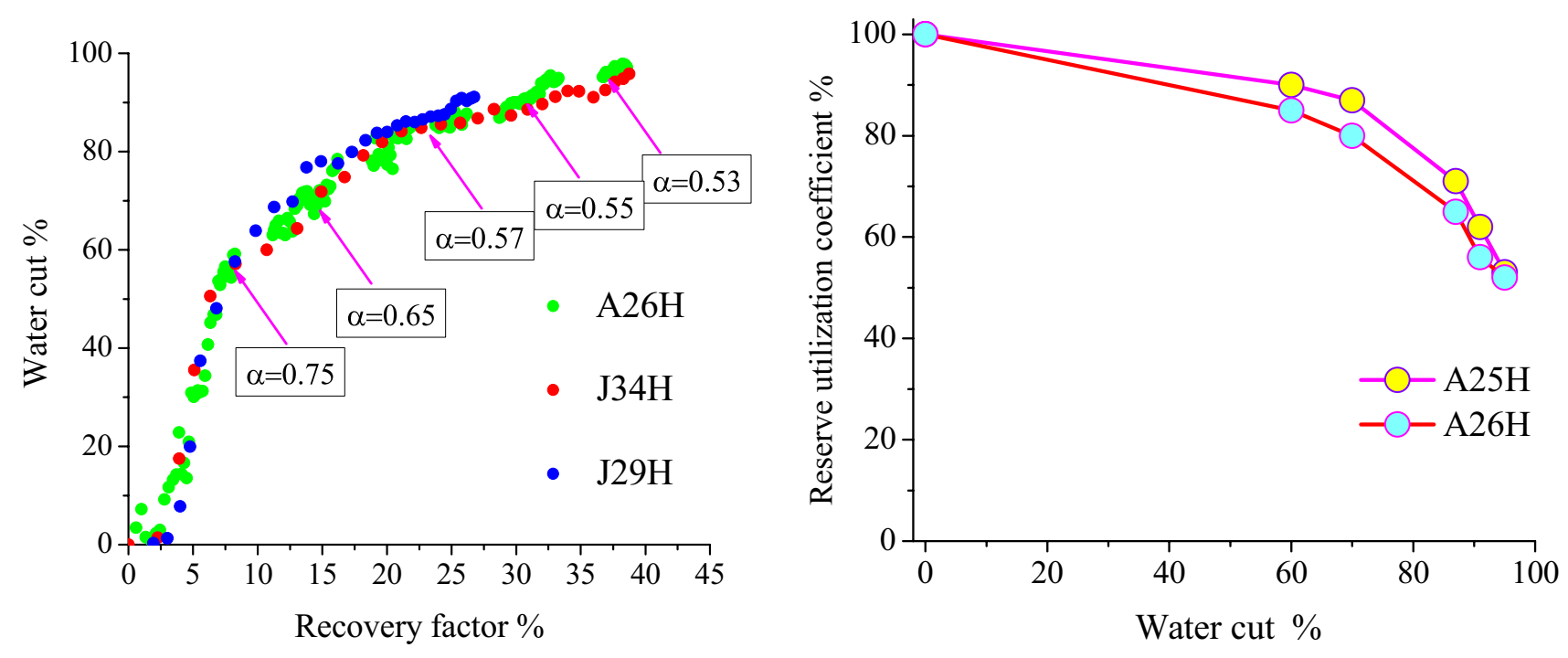

Fig. 6 How to estimate sweep efficiency of A26H well

Fig. 7 Horizontal well segment workflow

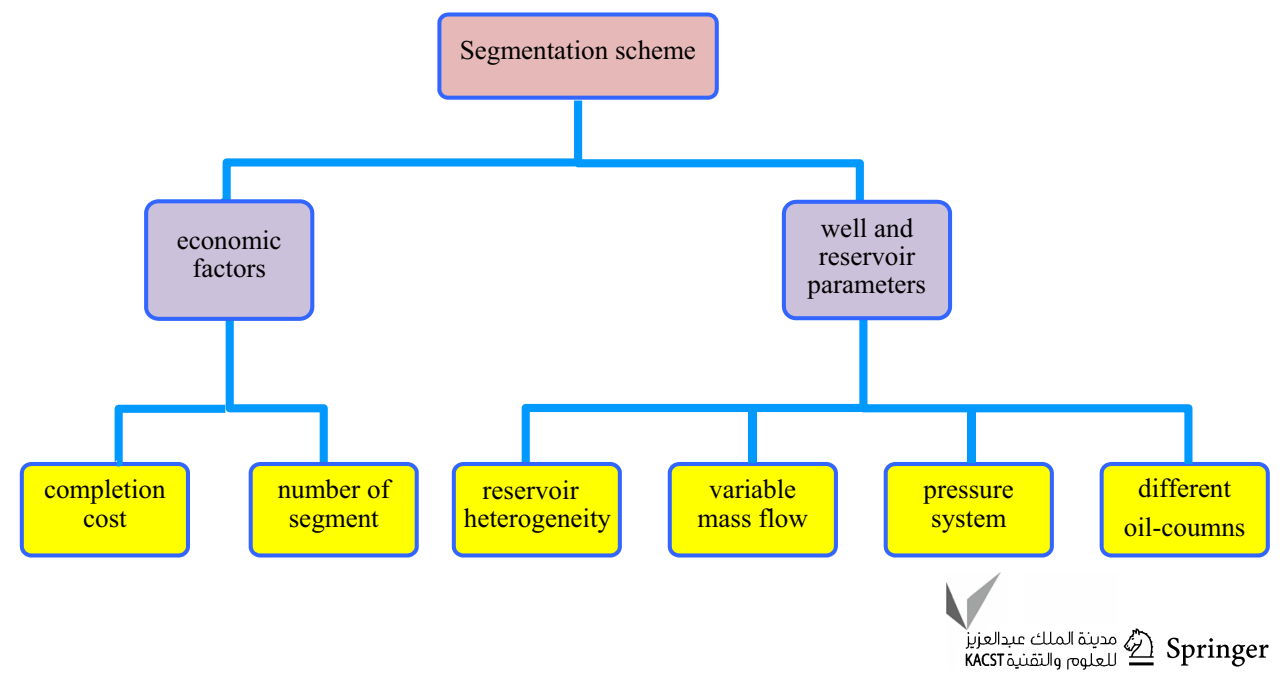


Fig. 8 The detailed segments of four plans

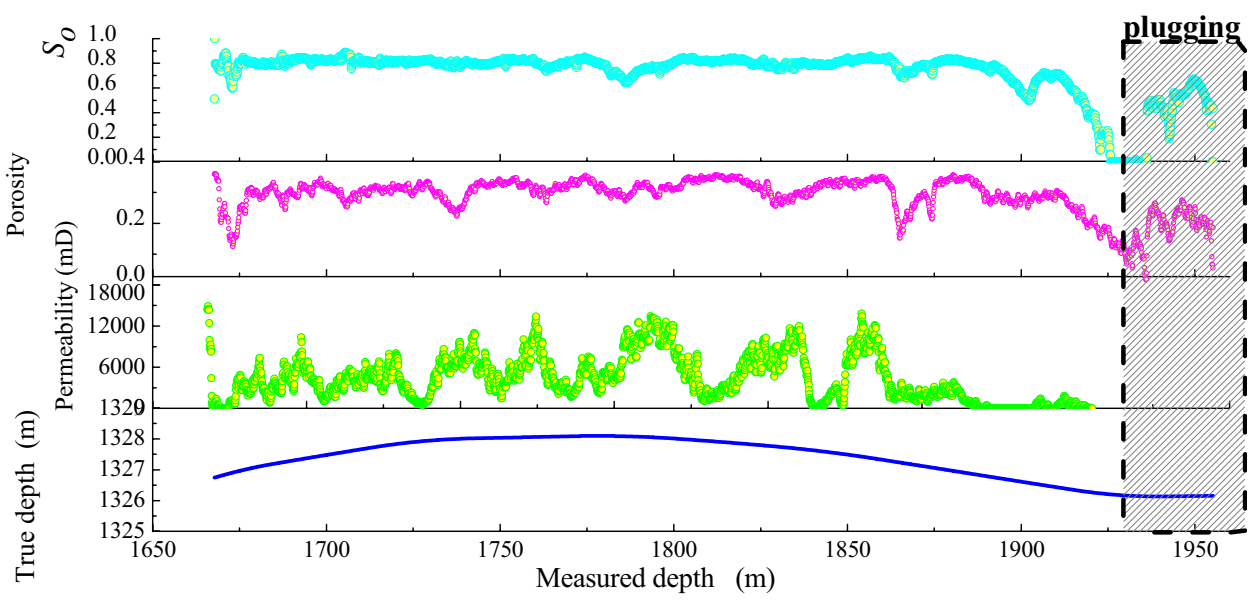

(a) first plan

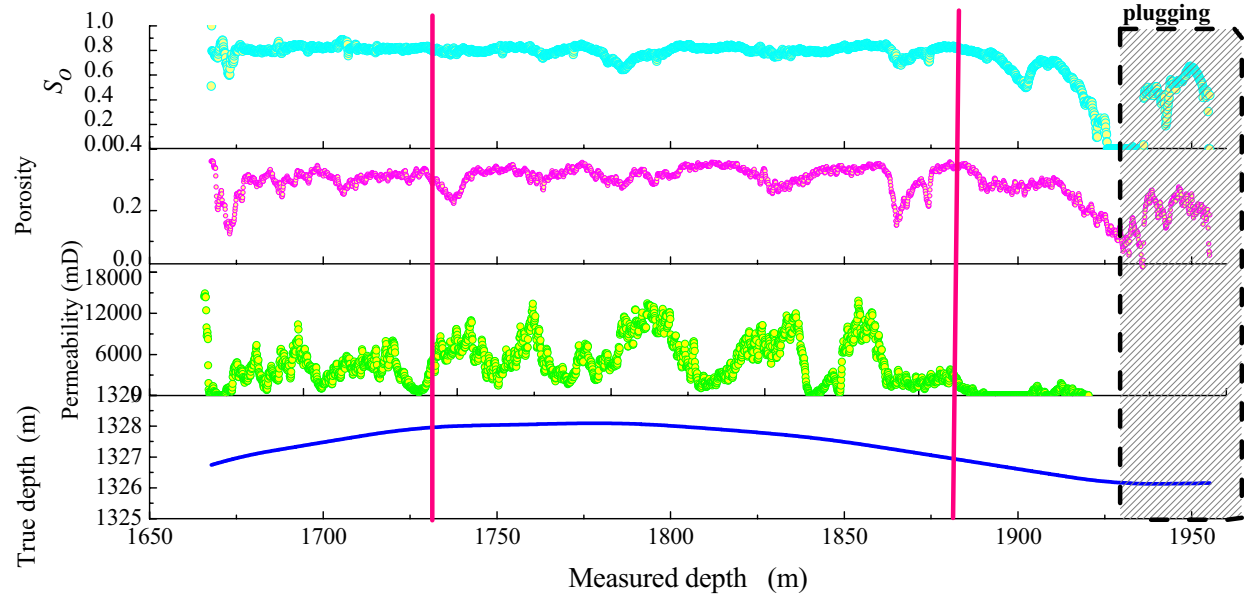

(b) second plan

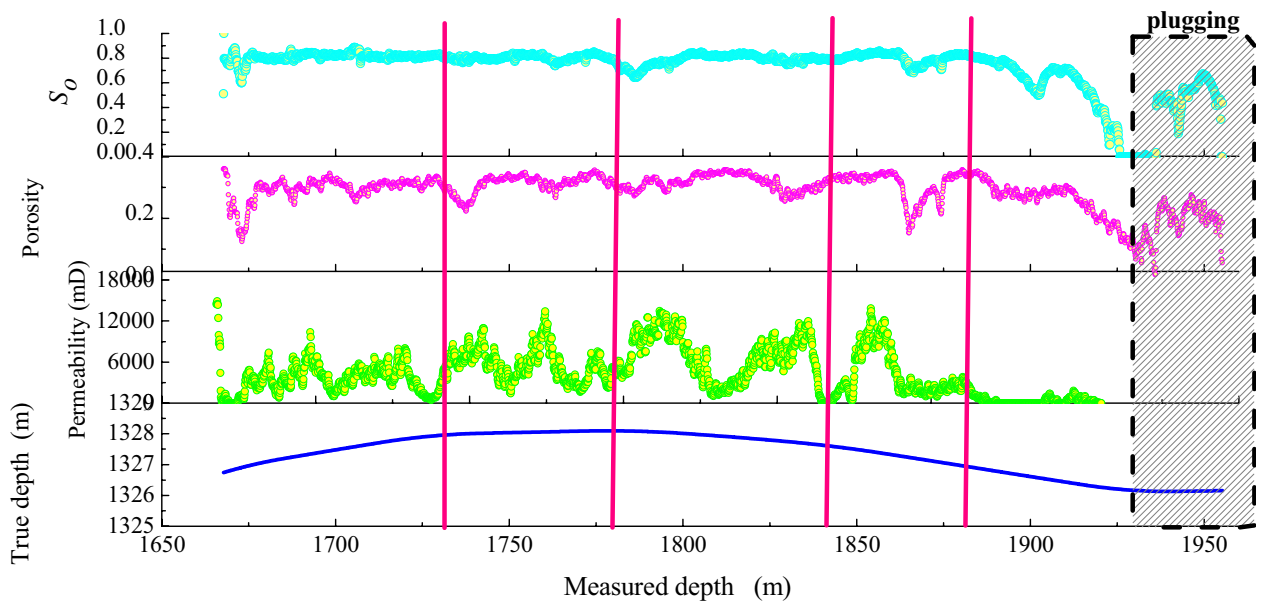

(c) third plan 
Fig. 8 (continued)

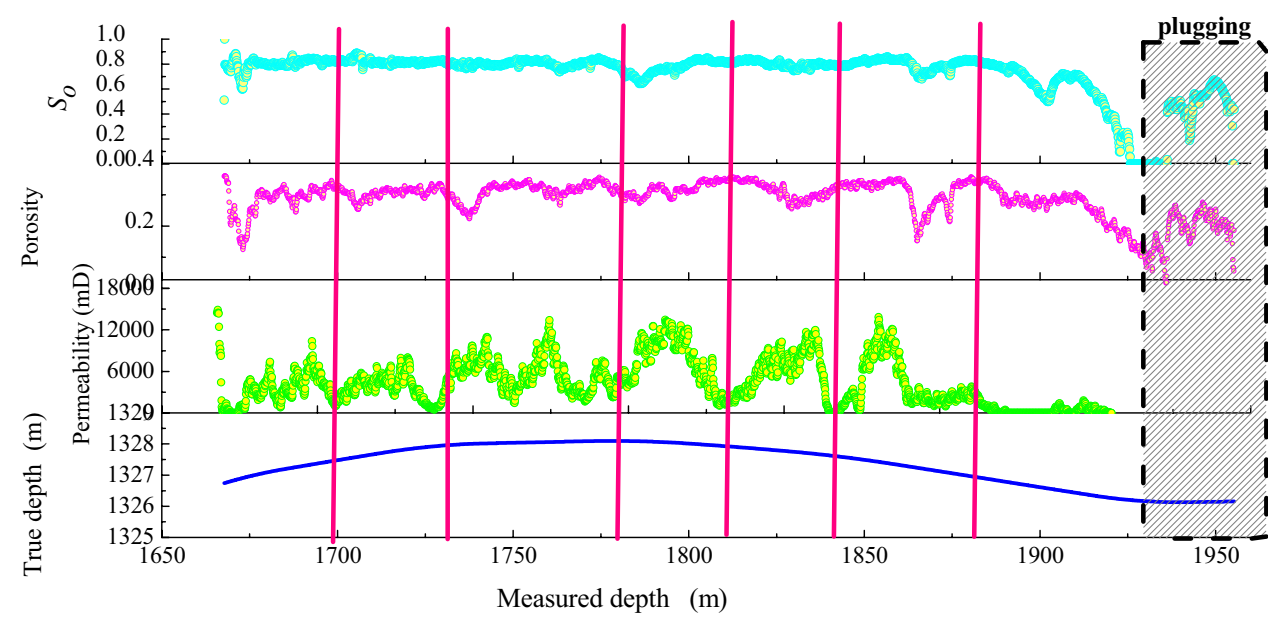

(d) fourth Plan

Fig. 9 The cumulative oil production of four plans

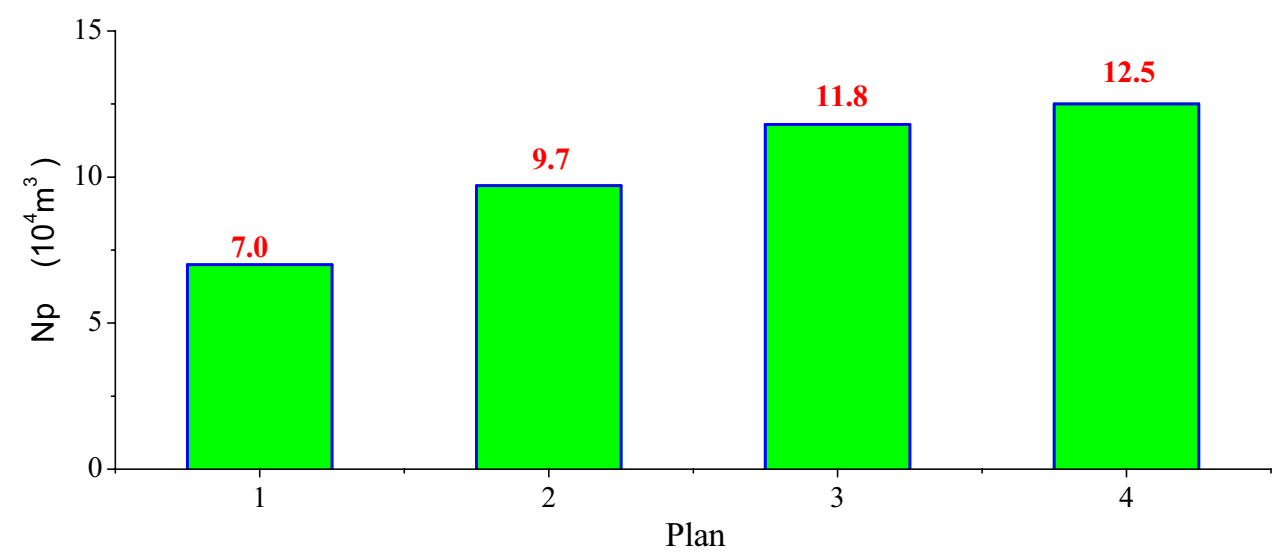

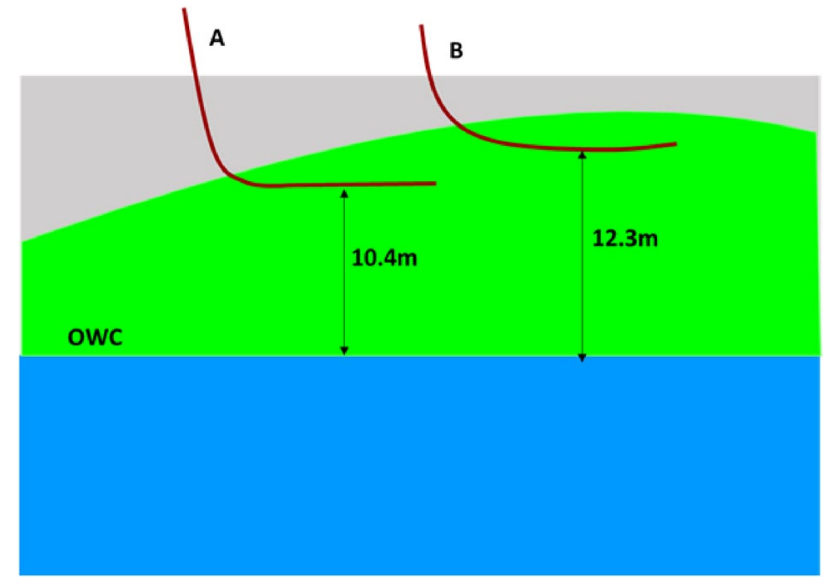

(a) Location of wells

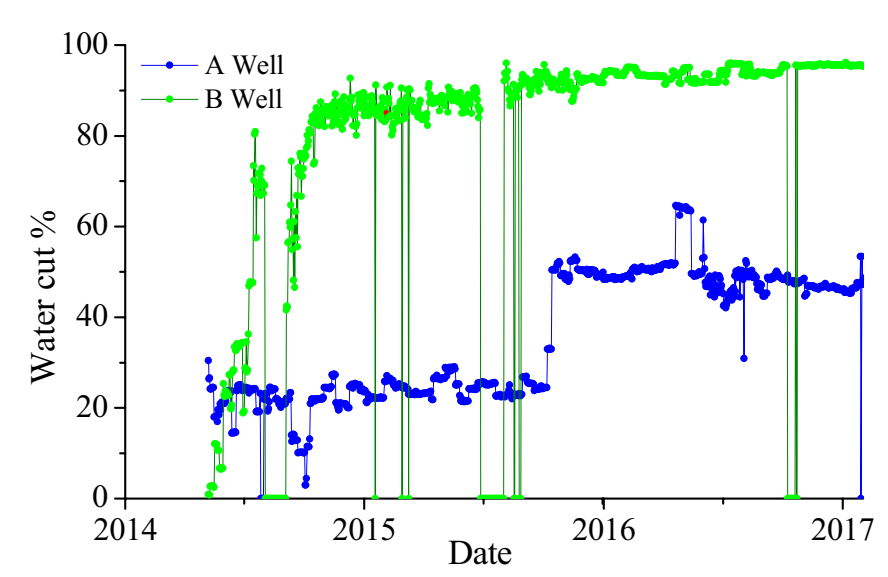

(b) Water cut increment of wells

Fig. 10 The comparison of wells A (ICD) and B (standalone) 


\section{Design, application and effect}

The application of ICD is not only more efficient, environmental friendly, reducing workover but also can improve the development effect of horizontal wells. The number and location of packers play the most important part in ICD design. The overall budget of well completion, reservoir heterogeneity, location of fracture, mudstone, abnormal highpressure zone and desired effect all play an important role in the final decision (Al Marzouqi et al. 2010).

First, we need to seal off the mudstone section and natural fracture zone directly connecting with bottom water. Second, we can make a prejudgment that the stronger the sand heterogeneity, the better the response of ICD. According to our research, the ICD is appropriate for the sand with permeability ratio less than 4 (Shi et al. 2016). In addition, the more the segments, the more uniform is the production profile. Meanwhile, overall budget should not be ignored. In a word, the location of packers depends on mudstone, permeability, aquifer and reservoir pressure. The workflow of ICD design is shown in Fig. 7.

An infill well (A well) of C oilfield was selected to install the ICD. Four well completion solutions were put forward based on LWD (logging while drilling) data and reservoir static information. It is important that we should get the most economic plan through numerical simulation.

There is no obvious difference in porosity and initial oil saturation. Therefore, the first plan is standalone besides the shale in the heel is plugged. In view of the TVD (true vertical depth), two packers were used in the second program. The reservoir heterogeneity is very strong in consideration of permeability. To minimize the permeability variation in each single section, another two plans were present. We can predict that the first is the lowest cost and the last is the highest cost (Fig. 8). The numerical simulation models were set up to accurately evaluate the economics of project (Fig. 9). Although the cost of ICD is beyond the scope of reservoir engineers, we can inferentially approximate that additional expenditure is justifiable and excessive packers is unnecessary. The third one is our final choice.

The well A is ICD completion and the well B is standalone completion. They were located at same sand and belonged to the same oil and water system with same bottom aquifer and same oil viscosity. Moreover, we make a water cut increment comparison between well $\mathrm{A}$ and well B. As shown in Fig. 10, the water cut of ICD well increases more slowly than well $\mathrm{B}$. The daily oil production of $\mathrm{A}$ is two times of $\mathrm{B}$ and liquid production of $\mathrm{A}$ is less than $\mathrm{B}$.

\section{Conclusions}

A brand new method was established to calculate the sweep efficiency of horizontal wells based on dynamic production data. Compared to the traditional PLT, the new method is more efficient and economically beneficial. The research illustrates that the optimal well length is dependent on reservoir heterogeneity. The design, optimization and application of ICD in a candidate well are presented in the paper. The development effect indicates that ICD can successfully delay the bottom water coning and reach the full potential of the reservoirs (Raffn et al. 2008).

Acknowledgements I would like to express my appreciation to my company for the permission to publish this paper. I wish to express my gratitude to my team for the technical support.

Open Access This article is distributed under the terms of the Creative Commons Attribution 4.0 International License (http://creativeco mmons.org/licenses/by/4.0/), which permits unrestricted use, distribution, and reproduction in any medium, provided you give appropriate credit to the original author(s) and the source, provide a link to the Creative Commons license, and indicate if changes were made.

\section{References}

Al Marzouqi ARA, Helmy H, Keshka AA-S et al (2010) Wellbore segmentation using inflow control devices: design and optimization process. In: Abu Dhabi international petroleum exhibition and conference. Abu Dhabi, UAE

Araque-Martinez AN, Lake LW (1994) Sweep efficiency estimates for reservoirs with nonuniform layers. In: Society of petroleum engineers, SPE-26973-MS

Chen SM, Olynyk J (1985) Sweep efficiency improvement using horizontal wells or tilted horizontal wells. In: Miscible floods. Petroleum Society of Canada, pp 36-62

Dashash AA, Al-Arnaout I, Al-Driweesh SM, Sarakbi SA, Al Shaharani K (2008) Horizontal water shut-off for better production optimization and reservoir sweep efficiency (case Study). In: Society of petroleum engineers, SPE-117066-MS

Mozaffari S, Tchoukov P, Atias J, Czarnecki J, Nazemifard N (2015) Effect of asphaltene aggregation on rheological properties of diluted athabasca bitumen. Energy Fuels 29:5595-5599

Mozaffari S, Tchoukov P, Mozaffaric A, Atias J, Czarnecki J, Nazemifard N (2017) Capillary driven flow in nanochannels-application to heavy oil rheology studies. Colloids Surf A Physicochem Eng Asp 513:178-187

Onur Balan H, Gupta A, Georgi DT, Alkhatib A, Marsala A (2016) Deep reading technology integrated with inflow control devices to improve sweep efficiency in horizontal waterfloods. In: Society of petroleum engineers, SPE-183566-MS

Raffn AG, Zeybek M, Moen T, Lauritzen JE, Sunbul AH, Hembling DE, Majdpour A (2008) Case histories of improved horizontal well cleanup and sweep efficiency with nozzle based inflow control devices (ICD) in sandstone and carbonate reservoirs. In: Offshore technology conference, OTC-19172-MS

Shi H, Zhou H, Hu Y, He Y, Fu R, Ren B (2016) A new method to design and optimize the ICD for horizontal wells. In: Offshore Technology Conference, OTC 26905-MS

Publisher's Note Publisher's Note Springer Nature remains neutral with regard to jurisdictional claims in published maps and institutional affiliations. 